\title{
O cinema na história. O uso do filme como recurso didático no ensino de história.
}

William Reis Meirelles ${ }^{1}$

\section{RESUMO}

Este texto trata de um projeto que pesquisa o uso do filme como documento histórico e como recurso didático no ensino de História, pois não podemos entender a história da sociedade humana a partir do século XX sem conhecer o cinema por ela produzido. 0 projeto tem por objetivo efetuar um inventário de filmes brasileiros tendo como fundamento propostas teóricas e metodológicas discutidas por Marc Ferro, Pierre Sorlin, Edgar Morin, Robert Stam entre outros pesquisadores que utilizam o cinema como documento histórico.

Palavras-chave: cinema e história, ensino de história, imagens brasileiras, fronteiras e populações

É claro que em revistas populares e programas de rádio, bestsellers, anúncios, modismos na linguagem e outros produtos sedimentares da vida cultural de um povo também fornecem informações valiosas. Mas o cinema excede a todas as outras mídias.

SIEGFRIED KRACAUER

Toda vez que ouço falar na exibição de um filme em uma aula de história ocorre-me algumas inquietações sobre o modo como está sento utilizado pelo professor. 0 que o professor deve considerar sobre o filme que apresenta aos alunos? Qual o significado desse filme enquanto testemunho histórico e 0 que acrescentará ao conteúdo de uma aula de história?

1 Professor do departamento de História Associado da Universidade Estadual de Londrina, Doutor em História e Sociedade pela UNESP-SP - wreism@uel.br. 
A utilização de imagens é recente no ensino e o filme cinematográfico aparece como matéria prima privilegiada em aulas de diversas disciplinas.

Neste texto serão discutidas questões abordando algumas constatações feitas ao longo do tempo e apresentadas algumas indicações, para que o uso do filme, especialmente o de fiç̧ão, se constitua em um instrumento de reflexão sobre a sociedade e seus modos de ser e não se transforme simplesmente num complemento para preencher algumas horas do calendário escolar.

As imagens enquanto documentos históricos - o cinema entre elas assumiram na recentemente reforma educacional status privilegiado como se pode constatar no texto dos Parâmetros Curriculares de Geografia e História:

Os documentos são fundamentais como fontes de informações a serem interpretadas, analisadas e comparadas. Nesse sentido, eles não contam, simplesmente, como aconteceu a vida no passado. A grande maioria não foi produzida com a intenção de registrar para a posteridade como era a vida em uma determinada época; e os que foram produzidos com esse objetivo geralmente tendem a contar uma versão da História comprometida por visões de mundo de indivíduos ou grupos sociais. Assim, os documentos são entendidos como obras humanas que registram, de modo fragmentado, pequenas parcelas das complexas relações coletivas. São interpretados, então, como exemplos de modo de viver, de visões de mundo, de possibilidades construtivas, específicas de contextos e épocas, estudados tanto na sua dimensão material (elementos recriados da natureza, formas, tamanhos, técnicas empregadas), como na sua dimensão abstrata e simbólica (linguagens, usos, sentidos, mensagens, discursos).

São cartas, livros, relatórios, diários, pinturas, esculturas, fotografias, filmes, músicas, mitos, lendas, falas, espaços, construções arquitetônicas ou paisagísticas, instrumentos e ferramentas de trabalho, utensílios, vestimentas, restos de alimentação, habitações, meios de locomoção, meios de comunicação. São, ainda, os sentidos culturais, estéticos, técnicos e históricos que os objetos expressam, organizados por meio de linguagens (escrita, oralidade, números, gráficos, cartografia, fotografia, arte). ${ }^{2}$

2 Parâmetros Curriculares Nacionais: bistória e geografia. Secretaria de Educação Fundamental. Rio de Janeiro: DP\&A., 2000, p. 79-81 (grifos nosso). 
A primeira questão a ser considerada é compreender qual o papel que o cinema, desde o seu nascimento, representa nas diversas formas da produção cultural, já que o filme é sempre uma forma de expressão de uma certa cultura inscrita em um determinado contexto sócio-histórico.

Para entender a importância da relação do cinema com história é importante ressaltar que esta alcançou o status de ciência e disciplina acadêmica no final do século XIX, ao mesmo tempo em que surgiam na indústria capitalista as inovações técnicas, como a fotografia, a gravura impressa, o cinema e o disco.

() uso do filme como documento histórico e como recurso didático no ensino de História é de grande importância, pois não podemos entender a história da sociedade humana a partir do século XX sem conhecer o cinema por ela produzido.

Através do filme podemos observar nos seus personagens a distribuição dos papéis sociais e os esquemas culturais que identificam os seus lugares na sociedade. As lutas, reivindicações e desafios presentes no enredo e os diversos grupos envolvidos nessas ações. 0 modo como aparece representada a organização social, as hierarquias e as relações sociais. Como são percebidos e mostrados pelos cineastas: lugares, fatos, eventos, tipos sociais, relações entre campo e cidade, rico e pobre, centro e periferia, etc.

o que um filme solicita do espectador em termos de identificações, simpatia, emoção com relação a determinado papel ou determinado grupo social, ou ainda determinada ação, rejeição com relação a outros; reflexão, ação etc.

Nessa perspectiva, a leitura de um filme em sala de aula deverá estar condicionada a um conhecimento prévio e sujeita à orientação bastante detalhada pelo professor.

É necessário que seja reconhecida uma circulação fluida de práticas que extrapolam as fronteiras sociais e o cinema é um dos muitos exemplos dos usos populares de idéias e códigos. Reconhecer que essas fronteiras são essencialmente o lugar da alteridade, o lugar de encontro dos que por diferentes razões são diferentes entre si.

Esse conflito imprime à fronteira uma dupla feição: lugar de descoberta e de desencontro. 0 tema evoca práticas econômicas, sociais e simbólicas que são elaboradas a partir da multiplicidade de concepções acerca do outro, do 
espaço e da natureza. Não apenas a confrontação de experiências, mas também, memórias, histórias sobre os processos de lutas e os imaginários sociais são aqui compreendidos. Nesse sentido as imagens cinematográficas colocam constantemente um projeto de construção e de enfoque da sociedade.

Partindo de tais constatações objetiva-se efetuar um inventário de filmes brasileiros tendo como fundamento as propostas teóricas e metodológicas discutidas por Marc Ferro, Pierre Sorlin, Edgar Morin, Robert Stam entre outros pesquisadores do cinema como documento histórico.

A pesquisa que vem sendo desenvolvida com a participação de alunos bolsistas bem como este texto é produto de resultados parciais acumulados a partir da experiência adquirida com a realização de um sub-projeto do Laboratório de Ensino de História da UEL - O Cinema Vai à Escola -, que chegou a sua quarta edição em 2000. 0 projeto visava atender pedidos individuais de professores do ensino médio, na cidade de Londrina, para organização e exibição de filmes que eram apresentados por docentes do Laboratório obedecendo a um projeto previamente preparado para atender a disciplina de História dentro do conteúdo programático de cada classe de alunos.

Em consequiência, a crescente demanda do projeto, cujos pedidos aumentavam a cada ano, tornou inviável o atendimento individualizado por várias razões entre elas o número reduzido de docentes que atuavam no Laboratório.

A partir das questões que se colocavam e dos problemas que se acumulavam o projeto tomou um novo rumo passando a preparar ações não mais voltadas para o micro, ou seja, o atendimento individualizado, mas para o macro, voltando seu foco para a organização de um banco de dados e a instrumentalização do professor para que ele próprio possa organizar seu ciclo de filmes de cinema com o assessoramento do Laboratório de Ensino de História. Esta etapa está atualmente em desenvolvimento e no momento seus esforços estão centrados na constituição do banco de dados inicialmente apenas de filmes brasileiros.

Os filmes serão selecionados através da análise de seus conteúdos (enredos) em correspondência com os conteúdos programáticos da disciplina de História no ensino médio. 0 banco será dividido em duas partes uma com filmes para a História do Brasil e outra para a História Geral. Para cada filme 
será elaborada uma ficha contendo as instruções de como utilizá-lo em sala de aula bem como propostas de atividades a serem desenvolvidas pelos alunos.

Com a alteraç̧ão de foco do projeto procura-se formar multiplicadores e através deles difundir o uso de novas técnicas no ensino de História através da utilização do cinema. Desse modo busca-se contribuir para a melhoria do ensino capacitando o professor para utilizar o cinema como recurso pedagógico nas suás aulas de história, através do banco de dados e de cursos ou de palestras que serão programados futuramente.

Após a organização do banco de dados pretendemos dentro das possibilidades realizar de uma terceira etapa do projeto, que será a constituição de um acervo de filmes em videocassete ou em dvd e que serão disponibilizados para estágio de alunos do curso de História da UEL bem como para os professores da rede para ser utilizado em sala de aula.

Para alcançar os objetivos propostos na pesquisa o projeto será divulgado através do Boletim do Laboratório de Ensino de História, assim como através de correspondência aos professores de História que fazem parte da mala direta do Laboratório e para o atendimento individual dos professores conta com uma sala no Instituto de Referência em Ciências Humanas da UEL. Os cursos e palestras serão organizados seguindo duas diretrizes, uma explorando um ciclo temático determinado e outra para atender propostas apresentadas por grupo de professores interessados.

Para alcançar os objetivos do projeto e mantê-lo em sintonia com as necessidades dos que dele se utilizam a sua eficácia será avaliada através de pesquisas qualitativas entre os usuários procurando detectar sua repercussão na comunidade e de que modo está contribuindo para a formação desses multiplicadores na rede de ensino.

Filme de Ficção Cientifíca: Um exemplo

Avançando em minhas considerações gostaria de apresentar algumas constatações sobre o uso do filme em sala de aula que foram registradas em encontros e discussões sobre o tema. Inicialmente apresentarei algumas indicações e em seguida algumas constatações.

o Cinema se constitui em uma importante fonte para o estudo da História. 
Como mostra Marc Ferro ele deve ser tomado no sentido de que o seu estudo associado às diversas instâncias que intervêm na sua realização se assenta em valioso repertório de atos e ações do homem, de testemunhos das construções do imaginário. o que dificilmente é alcançado pelas fontes tradicionais escritas.

Assim colocado o cinema pode, se constituir em uma importante fonte para o estudo da História. Isto no sentido de que o estudo do filme associado às diversas instâncias que intervêm na sua realização se assenta em valioso repertório de atos e ações do homem, de testemunhos das construções do imaginário, o que dificilmente é alcançado pelas fontes tradicionais escritas.

o Cinenıa pode, portanto, fazer parte do elenco das fontes da História, pelo que representáa como criação e como manifestação do imaginário. Seja por envolver um complexo processo econômico produtivo, como pela quantidade de inforinaçöes que contém e que nem sempre correspondem exatamente aos objetivos de seus autores, ou pelo seu valor enquanto testemunho de uma sociedade e de uma época.

Como um campo de possibilidades para resgatar ações de diferentes grupos

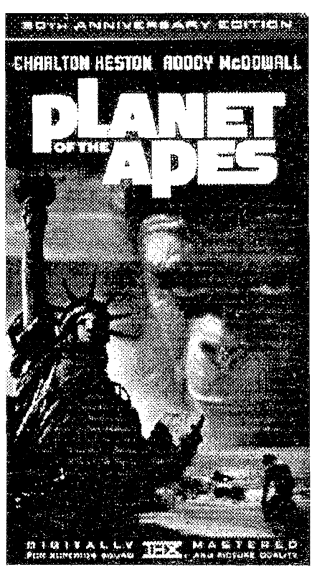
humanos atuando nas várias dimensões do social pode se constituir em um instrumento privilegiado proporcionando maior qualidade no ensino de História. o filme é, também, um campo de estudo para o historiador analisar o passado no que diz respeito ao aparecimento de uma visão da história tal como a imaginação sobre futuro esboça-a. Nesse sentido filme de ficção científica está carregado dessas visões de futuro impregnadas da mentalidade de uma época e, por excelência, é o repositório de medos, esperanças, desejos.

Um exemplo de sequiência de imagens que provocou um grande impacto nos espectadores

3 OPlaneta dos Macacos (The Planet of the Apes, 1968), Direção: Franklin J. Schaffner. Elenco: Charlton Heston, Roddy McIowall, Kim Hunter, Maurice Evans, James Whitmore, James Daly, Linda Harrison, Robert Gunner, Lou Wagner, Woodrow Parfrey,Jeff Burton, Buck Kartalian, Wright King. George Taylor (Charlton Heston), um astronauta americano. viaja por séculos em estado de hibernação. Ao acordar, ele e seus companheiros se vêem em um planeta dominado por macacos, no quál os humanos são tratados como escravos e nem mesmo tem o dom da fala. 
encontra-se no filme O Planeta dos Macacos ${ }^{3}$, e mostram o encontro dos astronautas de uma nave que caiu após sofrer uma pane, ao percorrer o território para reconhecer e buscar ajuda, após atravessar uma pequena elevação encontram a Estátua da Liberdade semi-enterrada na paisagem desértica; tal visão, pelo seu caráter insólito e inesperado, desconcerta os personagens ante a destruição de Nova York ocorrida enquanto estavam no espaço.

Impactos semelhantes carregados de uma visão catastrófica sobre futuro que está presente em nosso imaginário, especialmente com ênfase maior após o crescimento, a difusão e o debate empreendido pelos diversos grupos de defesa da natureza.

Alguns filmes têm como enredo temas que abordam o fim do mundo como ocorre em 0 dia seguinte ${ }^{4}$ onde seu realizador criou uma assustadora história dos efeitos causados pela explosão nuclear nos habitantes de uma pequena cidade dos Estados Unidos. Feito para exibição apenas na televisão, no entanto, a repercussão que alcançou levou seus realizadores a lançar nos cinemas. 0 sucesso que atingiu a fita se deu pela forma como os autores "imaginaram" o futuro e pelas questões que colocaram (o "acidente" que leva à guerra e suas consequiências), atraindo a atenção mundial.

Em períodos mais recentes outros filmes imaginam a destruição da terra, realizaçóes mais pretensiosas, como Independence Daý que apresenta o fim do mundo ante o ataque de alienígena e O Dia Depois de Amanhä $\tilde{a}^{6}$ cujo enredo

4 Odia seguinte (The Day After, 1983). DIREČ̃̃O: Nicholas Meyer: ELENCO:Jason Robards, Steven Guttenberg, John Cullum, Bibi lesech, Geor yam jol nnson. Na realização do filme foi utilizado tudo o que era conhecido sobre os efeitos de uma explosão atômiçı da radiação liberada por ela, o realismo da produção resultou em cenas chocantes. O interesse provocado pelo filme levou seus produtores a lançá-lo nos cinemas, no entanto o impacto que suas imagens provocavam acabou sendo proibida a sua exibição em muitos lugares, no entanto, jáem 20 de novembro de 1983 contabilizavaum público de cem millões de espectadores nos EUA.

5 Independence D)ay" (1996) Direção: Roland Enmerich.CCom: Will Smith, Bill Pullman, Jeff Goldblum, Mary McDonnell, Judd Hirsch, Margaret Colin, Randy Quaid, Robert Loggia, Harvey Fierstein, Harry Connick Jr. O filme foi feito segundo moldes da hipócrita onda annericana do politicamente correto. Os heróis são um negro (Will Smith) que namora uma stripper (Vivica Fox), um alcoólatra regenerado (Randy Quaid), um judeu (Jeff Goldblum), edeum bonzinhoe solícitopresidente americano (Bill Pullman).

6 ODia Depois deAmánhã (The Day Atter Tomorrow, 2004)Direção: Roland Emmerich. Elenco: Dennis Quaid, Jake Gyllenhaal, Emmy Rossum, Sela Ward, Arjay Smith, Tamlyn Tomita, Austin Nichols. A Terra sofre alterações climáticas de proporções inconcebíveis que modificann drasticamente a vida da humanidade enviando milhões de sobreviventes apavorados parao sul. Com o norte se resfriando cada vez maise passando por uma nova era glacial, millooes de sobreviventes rumam para o sul. Porém o paleoclimatologista Jack Hall (Dennis Quaid) segue o caminh ı inverso e parte para Nova York, agora uma cidade devastada e congelada jáque acredita que seu lilho Sam (Jake Gyllenhaal) ainda estávivo. 
procura mostrar/imaginar as consequiências do aquecimento global da Terra e uma mudança abrupta e catastrófica no clima provocada pelo efeito estufa. A destruição da Terra que esses filmes mostram é resultado dos possiveis efeitos que os movimentos ecológicos têm levantado e questionado sobre uma concepção equivocada de progresso sem considerar suas consequiências em relação a natureza, fato que contribuiu para a construção de um imaginário onde no futuro o mundo ama a sua própria destruição. Esse imaginário pode ser encontrado nos enredos cujos cenários se repetem em diferentes paisagens dos filmes realizados, especialmente, a partir dos anos 80. Os personagens de Blade Runner ${ }^{7}$, Mad-Max", ou Fuga de


lugares sujos, sombrios, nebulosos e ao mesmo tempo convivem com máquinas de tecnologias bastante sofisticadas.

\section{o Cinema na Era do Videotape e o DVD}

Um outro aspecto do cinema nestes últimos trinta anos, que deve ser considerado no seu estudo, é a popularização de inovações como o videocassete e atualmente o dvd, possibilitando a multiplicação do seu universo de influência

\footnotetext{
Blade Runner(1982) Direção: Ridley Scott. Elenco:Harrison Ford, Rutger Hauer, Sean Young, Edward James Olmos, M Emmet Walsh, Daryl Hannah. O filme mostra Los Angeles no ano de 2019, uma cidade totalmente cáticica, poluída, com milhões de pessoas amontoadas em ruas estreitas sob uma noite eterna e con uma miscelânea de etnias e dialetos. Nesse ambiente, seis andróides (espécie de clones humanos) fugitivos de uma colônia vivem clandestinamente no meios dos humanos e são procurados por homens treinados para caçar, identificar e "removê-los". O filme ébaseado no livro de Philip K. Dick chamado Do Androids Dream of Eletric Sheep?e foi escolhido em pesquisa recentemente como o melhor filme de ficção científica de todos os tempos

8 Mad-Max (1979). Direção: George Miller e George Ogilvie. Elenco: Mel Gibson, Bruce Spence, Adam Cockburn, Tina Tumer, Frank Thring, Angelo Rossitto, Paul Larsson, Angry Anderson, Robert Grubb, George Spartels, Edwin Hodgeman, Andrew Oh. Após a destruiçãa da civilização surge Bartertown, uma cidade no deserto com regras primitivas e mortais que tem uma governante (Tina Turner) que deseja consolidar seu poder a qualquer preço. Até que lá chega Max (Mel Gibson), que é forçado a participar de uma luta e, por ter se recusado a matar seu oponente, acaba sendo banido no deserto. Até que um grupo de jovens selvagens o salvam e passam a considerá-lo um messias que os levará até uma nova terra.

9 Fuga de Nova York (Escape From New York, 1981). Direção:John Carpenter. Elenco: Kurt Russell, Lee Van Cleef e Ernest Borgnine. Em 1997, o avião com o presidente dos Estados Unídos cai na cídade de Nova York, aģora transformada em uma penitenciária de segurança máxima. A única esperança é colocar em ação o ex-combatente de guerra e atual criminoso Snake Plissken (Russell) - que, em troca de sua liberdade, correrá contra o relógio para tentar salvar a vida do presidente.
} 
ampliando o seu campo de destinação inicial que era a exibição apenas nas salas destinadas exclusivamente para esse fim.

É a televisão que se mostra, hoje, o meio prioritário para difusão do cinema, basta verificar nas páginas dos grandes jornais onde se encontra a programação de cinema para constatar o espaço que os filmes ocupam na grade diária das redes de TV aberta e nos canais exclusivos de tv paga (Telecine, HBO, TNT. FOX, etc.), nestas exibindo, conforme anúncios na imprensa, até 1500 filmes por mês.

0 cinema, por outro lado, com o advento do videocassete e do dvd alcançou o "status" do disco, do livro, cada qual pode ter em sua casa sua "videoteca" particular. Nos dias de hoje, o mercado de cinema está voltado para a venda dos aparelhos de dvd e de filmes que podem ser facilmente adquiridos a preços módicos em bancas de jornal.

As inovações tecnológicas incorporadas nesses equipamentos (vídeo e dvd) possibilitam que o espectador manipule o filme alterando-o de diversas maneiras: voltando as imagens, repetindo seqüências, congelando quadros, mudando o tempo através da câmara lenta e tudo que a imaginação de cada um puder criar.

Algumas Contatações e Sugestões

Finalizando gostaria de apontar algumas constatações que a memória preservou ao longo do tempo de pesquisa e discussão sobre o uso do filme na sala de aula. Embora o cinema seja considerado um instrumento de relevante importância pedagógica, uma das principais questões reivindicada pelos professores do ensino médio e fundamental é a carência de uma bibliografia específica como apoio para que o professor possa utilizar o filme em sala de aula.

Outra questão para os professores diz respeito aos próprios filmes, que em sua maioria são longos - em torno de duas horas - e excedem a duração de uma aula.

Como proposta para esta questão podemos sugerir que a maneira para superar o problema do tempo e, ainda, alcançar resultados significativos, é organizar a exibição envolvendo a participação de outras disciplinas do curso (Geografia, Português, Educação Artística, Ciências, etc). Cada professor fará sua apresentação na perspectiva da sua área de atuação. Dessa forma, o filme 
pode tornar-se, muito mais interessante, visto que o envolvimento interdisciplinar estimulará o debate, tornando muito mais rica a sua compreensão.

A exibição do filme deverá ser precedida de uma apresentação pelo professor que deverá contemplar não apenas como o conteúdo mas, ainda, quais as motivações que presumivelmente levaram 0 autor a escolher 0 tema. Essa apresentação prévia não deverá, portanto, ficar limitada exclusivamente aos aspectos técnicos do filme, além da exposição da sinopse (resumo) da fita é importante indicar os momentos aos quais os alunos deverão observar para que o objetivo da aula seja plenamente atingido. 0 professor deverá estimular o aluno para refletir e fazer sua crítica sobre o filme apresentado, tornando-se um elemento eficaz no aprendizado da história e para que possa se constituir em um instrumento de reflexão sobre a sociedade nos seus modos de ser, não se limitando simplesmente para substituir o livro didático e preencher, com a exibição, algumas horas do calendário escolar.

Algumas questões apresentam-se quanto a disponibilidade de acervos de filmes em vídeo ou DVD que tenha uma duração compatível com a de uma aula, para que pudessem ser utilizados com maior constância, motivando a discussão e reflexão sobre os conteúdos da disciplina e, assim, tornar mais dinâmico 0 trabalho do professor.

Uma última questão a ser colocada é em relação ao o uso dos filmes históricos, que merecem uma reflexão mais aprofundada sobre a sua utilização procurando não fazer como geralmente acontece, de um modo positivista, ou seja como se fossem construções do passado. Tais filmes são, também, construções como a história, e portanto incorporam uma motivação do presente, como exemplo, podemos citar o filme Danton, o processo da revoluçãa ${ }^{10}$ através do qual o autor usa uma passagem da história da Revolução Francesa para fazer uma crítica ao momento presente do governo polonês, o general Wojciek Jaruselski, que proibira o sindicato independente Solidariedade, por considerá-lo um movimento popular de resistência ao regime. Portanto, diante

\footnotetext{
${ }^{10}$ Danton(1982, França/Polônia). Direção: Andrzej Wajda. Ea.zNCO: Gérard Depardieu, Wojciech Pszniak. Durante a fase popular da Revolução Francesa, instala-se $\mathrm{c}$ período do "terror", quando a radicalização revolucionária dos jacobinos encabeçada por Robespierre inicia um violento processo político com expurgos, manipulação de julgamentos e uma rotina de execuções pela guilhotina.Danton, líder revolucionário, critica os rumos do movimento, tornando-se mais uma vítima do terror instalado por Robespierre.
} 
da rígida censura estatal, o diretor Andrzej Wajda estrategicamente utilizou um acontecimento do passado para criticar o presente. Quanto as suas intenções não deixa dúvidas pois basta verificar o ator que representa Robespierre é um sósia quase perfeito do general Jaruselski.

Outros exemplos podem ser lembrados, como os filmes brasileiros Independência ou Morte ${ }^{11}$ de Carlos Coimbra e Carlota Joaquina ${ }^{12}$ de Carla Camurati. 0 primeiro filme, pode ser considerado quase como uma encomenda do general presidente da época e referenda uma construção conservadora da nossa história, ainda, encontrada em muitos livros didáticos. 0 segundo filme mostra alguns personagens da história destituídos de qualquer importância, banalizando-os e marcando-os apenas pelas características de suas personalidades um tanto exóticas. ${ }^{13}$

Bibliografia

BARBERO, Jesus Martin. "A comunicação no projeto de uma nova cultura política". In: MELO, José Marques de (org.). Comunicação na América Latina: Desenvolvimento e Crise. Campinas, Papirus, 1989.

FERRO, Marc. "O filme: uma contra-análise da sociedade?". In: LE GOFF, Jacques e NORA, Pierre. História: Novos Objetos. Rio de Janeiro, Francisco Alves, 1976.

FERRO, Marc. A manipulação da bistória no ensino e nos meios de comunicação. São Paulo, IBRASA, 1983.

"Independência ou Morte(1972). Direção: Carlos Coimbra. Elenco: Tarcísio Meira (Dom Pedro I), Glória Menezes (Marquesa de Santos), Dionísio Azevedo (José Bonifácio), Kate Hansen (Dona Leopoldina), Emiliano Oueiroz (Chalaça), Manoel da Nóbrega (Dom João VI), Heloísa Helena (Carlota Joaquina). 0 filmé ú uma versão da independência que "dava ao governo militar uma espécie de miragem de si refletida no passiádo, bem como explicitava para si e a qualquer um como gostaria de ser designado naquele momento, pois sua autoridade se espelharia em D. Pedro I, a integrar o território nacional, defendendo-o do que considerava os adversários políticos internos e externos, ao pautar-se pela ideologia da Segurança Nacional". (SCHIAVINATTO, p. 83)

12 Carlota Joaquina, Princesa do Brasil (1995). Direção: Carla Camurati. Elenco: Marieta Severo, Marco Nanini, Ludmila Dayer, Maria Fernanda, Marcos Palmeira, Antonio Abujamra, Vera Holtz, Ney Latorraca. A morte clo rei de Portugal D. José I em 1777 e a declaração de insanidade de D. Maria I em 1972, levam seu filho D. João e sua mulher, a espanhola Carlota Joaquina, ao trono português. Em 1807, para escapara das tropas napoleônicas, o casal se transfere às pressas para o Rio de Janeiro, onde a família real vive seu exílio de 13 anos. Na colônia aumentam os desentendimentos entre Carlota e D. João VI.

${ }^{13}$ As referências e fichas dos filmes citados foram levantados em páginas da internet e em guias de vídeos publicados pela Nova Cultural. 
FERRO, Marc. História Vigiada. São Paulo, Martins Fontes, 1989.

MEIRELLES, William R. "Cinemae História: Considerações de um objeto de estudo. HISTÓRIA \& ENSINO Revista do Laboratório de Ensino de História/UEL, Londrina: v. 1, 1995.

MEIRELLES, William R. "História das Imagens: uma abordagem múltiplas facetas" PÓS-HISTÓRIA, UNESP. ASSIS, ñ. 3, 1995.

MEIRELLES, William R. Paródiu e Chanchuda: Imagens do Brasil na Culiura das Classes Populares. Assis, UNESP, 1998. Tese de Doutorado (datil.).

RAMOS, José Mário Ortiz. Cinema, Estado e Lutas Culturais (50 / 60 / 70). Rio de Janeiro, Paz e Terra, 1983.

Revista USP. "Dossiê Cinema Brasileiro". São Paulo, USP, 19, Setembro / Outubro / Novembro, 1993.

SCHIAVINAT'T'O, larad Lis. A pruça pública e a liturgia política. In: Cad. Cedes, Campinas, v. 22, n. 58 , p. 81-99, dezembro/2002.

STAM, Robert. "Cinema e Multiculturalismo". In: XAVIER, Ismail (org.). O Cinema no século. Rio de Janeiro, Imago, 1996, p. 197/214.

\title{
The cinema in the history. \\ The use of the film as a didactic resource in History teaching.
}

\begin{abstract}
This text treats of a nroject that researches the use of the film as a historical document and as a diclactic resource in History teaching, for we cannot understand the history of the human society starting from the XX century without knowing the movies produced by it. The project has for objective to make an inventory of Brazilian films using as a foundation theoretical and methodological proposals discussed by Marc Ferro, Pierre Sorlin, Edgar Morin, Robert Stam among other researchers that use the movies as historical document.
\end{abstract}

Keywords: cinema and history, history teaching, brazilian images, borders and populations. 